\title{
Radiation Protection by the Barite Coated Fabrics via Image Processing Methodology
}

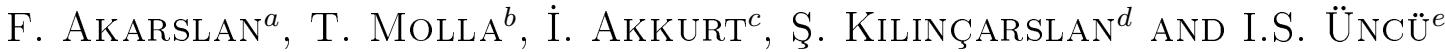 \\ ${ }^{a}$ Suleyman Demirel Univ., Engineering Fac., Tekstile Eng. Dept., Isparta, Turkey \\ ${ }^{b}$ Suleyman Demirel Univ., Technical Education Fac., Construction Dept., Isparta, Turkey \\ ${ }^{c}$ Suleyman Demirel Univ., Sience Fac., Physics Dept., Isparta, Turkey \\ ${ }^{d}$ Suleyman Demirel Univ., Engineering Fac., Civil Engineering Dept., Isparta, Turkey \\ ${ }^{e}$ Suleyman Demirel Univ., Technology Fac., Elec. and Electr. Dept., Isparta, Turkey
}

\begin{abstract}
According to developing technology and conditions of modern life, use of radiation is rapidly increased. Unwittingly, our organs and tissues are exposed to radiation continuously. In order to avoid exposure to this radiation, some studies were carried out on protective clothing. In this study, radiation keeping properties of the fabrics coated with barite are examined. Radiation keeping properties were also determined by the method of image processing. After the experiments, it is determined that barite-coated fabrics absorb radiation better than normal fabrics.
\end{abstract}

DOI: $10.12693 /$ APhysPolA.125.316

PACS: 42.88. + h, 28.41. $-\mathrm{i}$

\section{Introduction}

There are many types of radiation from various sources, such as cosmic rays from space and sun, radioisotopes on earth's crust, natural and artificial sources are exposed to radiation from natural sources in the earth and the atmosphere. An average yearly effective dose from this so-called natural background amounts to about $2.5 \mathrm{mSv}$. Artificial sources - except medicine - add very minute doses to population at large [1]. To know the radiation tolerance limits of each organ and area of the body is the most important key factor to protect people working at radiated environment and community from radiation poisoning [2]. Radiation protection, sometimes known as radiological protection, is the protection of people and the environment from the harmful effects of ionizing radiation, which includes both particle radiation and high energy electromagnetic radiation. Radiation doses should all be kept as low as reasonably achievable [3].

To date, there have been many studies of fabric production for radiation protection. The vast majority of these studies were concerned with fabric production against sunburn (for UV protection), and the rest of them were on the fabric production against electromagnetic radiation [4-8]. Although lead shielding as one of the conventional methods is well known shielding for radiation, application takes long time, needs special labour, and it is expensive and dangerous for health [9]. Thus, researchers are oriented to find alternatives having shielding property, not being harmful for health and useful. Application practicality of barite mineral will save time, provides low cost and removes the factors threat for human health. Barite $\left(\mathrm{BaSO}_{4}\right)$ is a mineral consisting of barium sulphate. It contains barium mineral which has high radiation keeping properties [10].

Due to the barium element which is in barite, the unit weight is higher. The Mohs hardness 3, refractive index
1.63 , specific gravity $4.3-5$. Barite is used for protection against the lethal effect of neutron and gamma rays and minimizes the effect of the radiation. Fibers are obtained from the alpaca by shearing it [11]. According to its strength, brightness and the structure which has air gaps in microscopic size that keeps air, it is warmer 7 times than wool.

\section{Materials and methods}

\subsection{Materials}

In this study, the barite is used in $20 \mu \mathrm{m}$ scale from the barite formations which are in the vicinity of the town S. Karaağaç of Isparta. The analysis showed that the density of barite is $4.20 \mathrm{~g} / \mathrm{cm}^{3}$. Alpaca fabric is used because of the fibrous structure and it is preferred for making aprons. In this study, in the weight of $180 \mathrm{~g} / \mathrm{m}^{2}$, warp (density) frequency: 30, weft frequency: 24, weaving type: $1 / 1$ (the $z$ direction), $25 \%$ viscose, $75 \%$ polyester was used. FK $800 / \mathrm{N}$ type transparent as adhesive and HT 801 type hardener was used.

\subsection{Methods}

\subsubsection{Barite coating on cloth}

$\mu \mathrm{m}$ sized barite was prepared by mixing with "adhesive" and "hardener" water-based additives. The mixture is in fluid consistency and it contains $50 \%$ barite, $25 \%$ water, $22.5 \%$ adhesive, and $2.5 \%$ hardener. Fabrics to be coated were fixed on the smooth ground and then silk stretched on metal sash was placed on the surface of that cloth. Glue mixture prepared by adding barite was perfused to penetrate on the surface of cloth equally. Clothes were fixed after coating process. This process was performed via succession of heating and cooling.

\subsubsection{Determination of radiation keeping property}

Radiograms of clothes perfused by barite via coating method were made at radiology unit, at 70 MAS en- 
ergy in order to determine radiation keeping property and were recorded. Two different radiograms of clothes were made as not coated and coated.

X-ray beam passing through materials having high atomic intensity reaches to the film in a very little amount. They are seen on the film as light grey and white. Film changes as white, grey scale and black with respect to the X-ray permeation portion.

\subsection{Image processing}

Adsorbed amount of X-ray beam can be determined due to this situation. Colour of cloth absorbing X-ray (radiation) more was close to white and not absorbing is close to black. This process can be distinguished computationally by image processing method.

Digital image of the Röntgen films obtained were subjected to pre-treatment and then size of them changed to $2350 \times 2350$ pixels. Images were converted from RGB colour mode to 8 bit grey colour tones. An image has 256 different colour tones. 0 colour tones is corresponding to black and 255 colour tone is white as a rule. Horizontal axes and vertical axes represent tone value and number of pixel, respectively.

Radiation keeping image processing value (RKIPV) can be calculated by dividing sum $\left(\sum a b\right)$ of multiplication of horizontal excess values $(a)$ and vertical axes pixel numbers $(b)$ by total colour tone value $\left(\sum a\right)$ :

$$
\text { RKIPV }=\frac{\sum a b}{\sum a} .
$$

\subsection{Gamma spectroscopy methods $(\mu)$}

The linear attenuation coefficients $(\mu)$ of the fabrics were measured at the photon energies of $1332 \mathrm{keV}$ obtained from ${ }^{60} \mathrm{Co} \gamma$-ray sources. As detailed elsewhere, the measurement has been performed using the gamma spectrometer that contains $\mathrm{NaI}(\mathrm{Tl})$ connected to $16 \mathrm{k}$ channels multi-channel-analyser (MCA).

The communication of the system is done using Maestro-32 software

$$
N=N_{0} \mathrm{e}^{-\mu x} \text {. }
$$

The linear attenuation coefficients have been evaluated comparing $N$ and $N_{0}$, which are the measured count rates in detector, respectively, with and without the absorber of thickness $x(\mathrm{~cm})$.

\section{Results}

Digital Röntgen images of clothes taken under $70 \mathrm{keV}$ were converted to histograms by using commercial program. Figures 1 and 2 show Röntgen images of clothes and histograms (shortened to non-zero of 255 channels) of clothes, respectively.

Colour of digital Röntgen image of not coated cloth shown by Fig. 1 was near black. Colours of digital Röntgen images of clothes were getting whiter with the increase on number of coating (coated layer) (Fig. 2).

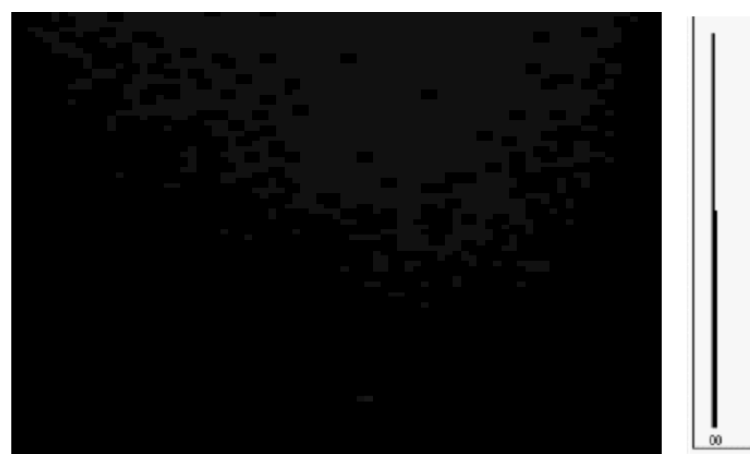

Fig. 1. Digital image transaction and digital image histograms of a not coated (normal) cloth.
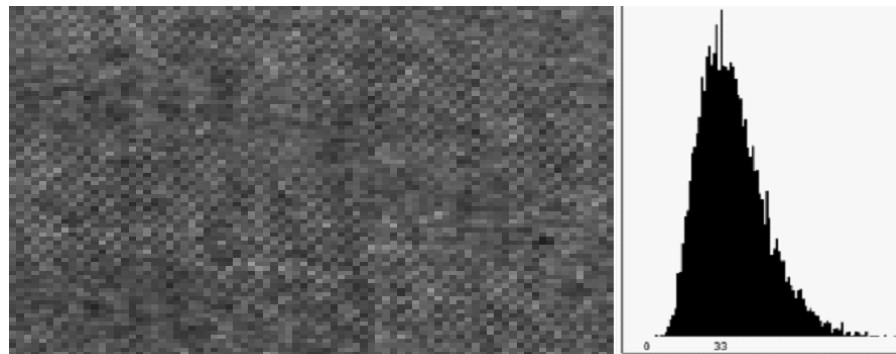

Fig. 2. Digital image transaction and digital image histograms of 1 times barite coated cloth.

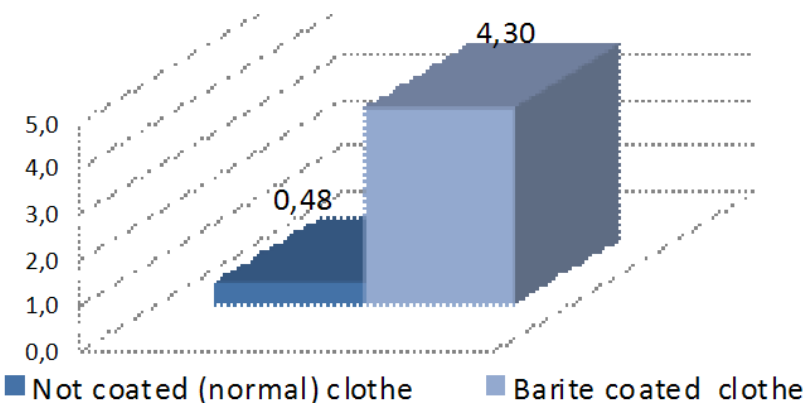

Fig. 3. The fabrics numerical value of RKIPV.

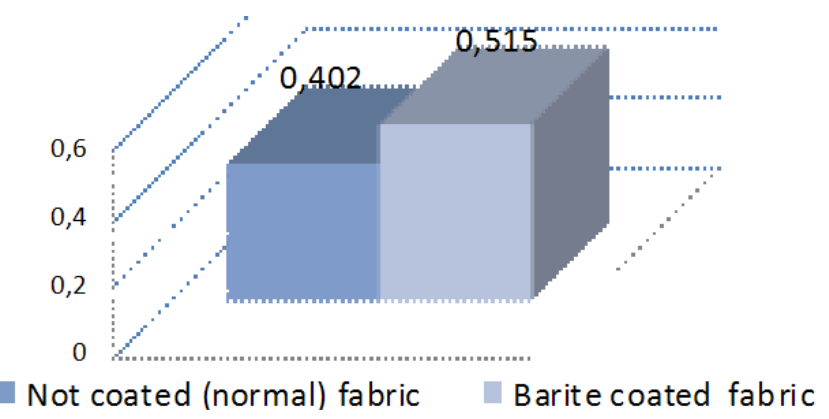

Fig. 4. Linear attenuation coefficient $\mu$ values $(1332 \mathrm{keV})$. 
Histogram shown by Fig. 1 and 2 designates that colour tone value of not coated cloth is near " 0 " and the colour tone value is in a small interval. Tone values were increased in coated fabric.

The highest colour tone values and corresponding pixel numbers obtained from histograms of clothes having Röntgen images at Fig. 3. The linear attenuation coefficients for the fabrics are given in Fig. 4.

\section{Conclusions}

The colour of the digital Röntgen image of not coated fabric was nearly black whereas for coated fabric is nearly grey. This investigation was confirmed with histograms obtained. There were linear relationships between RKIPV obtained from histograms and radiation keeping property. Radiation keeping capacity was high due to high value of RKIPV. Radiation keeping property of cloth having homogeny barite penetration was developed. Barite coated fabrics have absorbed more radiation with respect to not coated (normal) fabrics so thus blocked radiation passage to the body. It was seen that linear attenuation coefficient $\mu$ value increased by $28 \%$ and was compatible with image processing. It is observed that barite coated fabrics absorbed radiation with the image processing method and gamma spectroscopy method. The adverse effects of radiation to human health will be absorbed and the dose will be reduced owing to barite coated fabrics.

\section{Acknowledgments}

The authors wish to thank the TÜBİTAK for supporting this work with the project number of $112 \mathrm{M} 373$.

\section{References}

[1] ICRP Publication 116: Conversion Coefficients for Radiological Protection Quantities for External Radiation Exposures Annals of the ICRP, Vol. 40, iss. 2-5.

[2] ICRP Publication 60: International Commission on Radiological Protection, Annals of the ICRP, Vol. 21, publ. 60, Pergamon Press, Oxford 1990.

[3] A. Kaul, D. Becker, Radiological Protection, Springer, New York 2005, Vol. XVIII.

[4] M. Akaydın, Y. İkiz, N.S. Kurban, Textile Confection 3, 212 (2009).

[5] W.Y. Chiang, K.Y. Cheng, Polym. Compos. 18, 748 (1997).

[6] D. Saravanan, Autex Res. J. 7, 53 (2007).

[7] K. Duran, M.İ. Bahtiyari, R. Atav, Textiles Confections 17.3, 174 (2007).

[8] N. Merdan, K. Acar, The Applications of $U V A b$ sorber on Textiles, İstanbul Ticaret Üniversitesi, Fen Bilimleri Dergisi, Vol. 8, 2009, p. 1.

[9] Ş. Kılınçarslan, C. Başyiğit, I. Akkurt, J. Fac. Eng. Arch. Gazi Univ. 22, 393 (2007).

[10] S. Kilıncarslan, I. Akkurt, T. Molla, F. Akarslan, AIP Conf. Proc. 1476, 52 (2012).

[11] S. Çoban, General Textile Finishing and Finishing Processes, No 6, Ege University, Textile and Apparel Research-Application Centre Publishing, İzmir 1999 (in Turksih). 